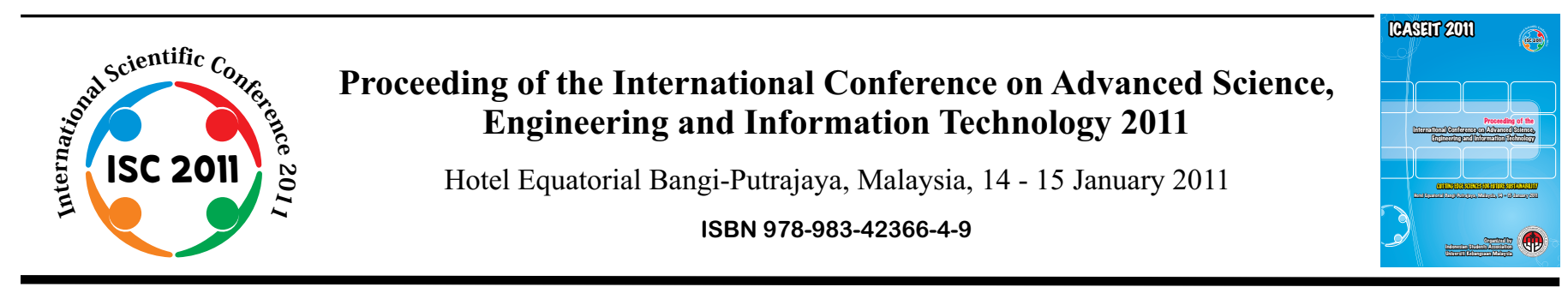

\title{
Critical Success Factors for Enterprise Resource Planning System Implementation: A Case Study in Malaysian SME
}

\author{
Feybi Ariani Goni ${ }^{1}$, Abdoulmohammad Gholamzadeh Chofreh $^{2}$, Shahnorbanun Sahran ${ }^{3}$ \\ ${ }^{I}$ Pusat Pengajian Sains Komputer, Faculty of Information Science and Technology, Universiti Kebangsaan Malaysia \\ Universiti Kebangsaan Malaysia, 43600 Bangi, Selangor, Malaysia \\ Tel.:+603-89216179, E-mail:fey2chan@yahoo.com
}

${ }^{2}$ Business of Administration, Faculty of Management, Multimedia University

Cyberjaya Campus, Jalan Multimedia, 63100 Cyberjaya, Selangor, Malaysia

Tel.:+603-83125099/5109,E-mail:mohammad_apmie@yahoo.com
${ }^{\text {I}}$ Pusat Pengajian Teknologi Maklumat, Faculty of Information Science and Technology, Universiti Kebangsaan Malaysia Universiti Kebangsaan Malaysia, 43600 Bangi, Selangor, Malaysia
Tel.:+603-89216729, E-mail: shah@ftsm.ukm.my

\begin{abstract}
Implementing Enterprise Resource Planning (ERP) system for Malaysian Small to Medium Enterprises (SMEs) is not just a technological challenge. It is a socio-technological endeavour which mandates modifying existing applications and redesigning business processes to facilitate ERP system implementation. Most Malaysian SMEs cannot afford to adopt an existing ERP system due to the extremely high cost and complex implementation. The ERP system implementation literature contains many case studies of organizations that have implemented ERP system successfully. However, many Malaysian SMEs do not achieve success in their ERP system implementation. There are very few studies have represented and developed critical success factors of ERP system implementation projects highlighted for SMEs. This research seeks to explore the critical success factors for successful ERP system implementation in Malaysian SMEs. The research method is based on a case study within Malaysian SME to perform a critical success factors model of ERP system implementation adoption which has validated by a number of SMEs in Malaysia. The proposed model will help outline the critical factors that should be considered by Malaysian SMEs in successfully adopting ERP system.
\end{abstract}

Keywords - Critical Success Factors, Enterprise Resource Planning, Small to Medium Enterprises.

\section{INTRODUCTION}

The business global competition gives pressuring in many organizations to change their information system strategies by adopting more advanced application software packages. An advanced application software package such as ERP system is one of the choices to overcome some problems in Malaysian SMEs. ERP is an information system designed to coordinate all the resources, information, and activities needed to complete business processes [1]. ERP system, which is commercial software package that enables the integration of transactions-oriented data and business functions throughout an enterprise, holds the potential of greatly enhancing organizational performance and establishing competitive advantage [2]. One of the most important technological innovations of the last decade has been the emergence of ERP solutions. However, the benefits of ERP system cannot be easily acquired as a technology solution for Malaysian SMEs [3]. Most Malaysian SMEs cannot afford to adopt an existing ERP system due to the extremely high cost and complex implementation of the system.

In previous research surveys reported that three quarters of the ERP system projects were judged to be unsuccessful [4]. Based on [5] research finding, there are several reasons for unsuccessful ERP system implementation: (1) The low level of awareness amongst SMEs for ERP vendors and applications. SMEs do not even know what ERP systems are 
and what they can do. They consider ERP systems to be a magic wand, which will help solve all their business problems, (2) SMEs have the perception that ERP is meant only for large firms mainly owing to the high costs of acquisition, implementation and maintenance as also the complexity. Some of the SMEs even feel they do not need ERP system, (3) SMEs have heard of the much-publicized failures in ERP implementation, which have led firms to bankruptcy. Some SMEs who have implemented ERP earlier have failed. This has led SMEs to believe that ERP implementations are a waste of time and effort and can even lead to the demise of company, (4) SMEs approach to ERP system implementation. ERP vendors' advice SMEs to mould the business to ERP's way of working, considering that ERP systems bring with it best business practices. But most SMEs have processes that they have evolved over time and hold very dear to their hearts. As a result, SMEs are having the entire ERP system customized to meet their requirements. This would increase the overall cost of implementation. A good approach would be to keep the customization to a minimum, (5) SMEs have less of capital than their larger counterparts, (6) Change management issue. People are not ready to accept the change of their original works, (7) SMEs have limited resources. Most SMEs do not have an in-house IT team. Due to this they have to rely on external agencies to help them and this adds to the implementation costs.

All of ERP system implementation issues mentioned in previous section are explored in this study as critical success factors for ERP system implementation in Malaysian SMEs. This paper is organized in three sections. First, literatures review related to critical success factors of ERP system implementation. The next section introduces the research methodology and the proposed model for successful ERP system implementation. In the end, the research discussion and conclusion made based on the learning outcomes from this case study for future research and practice in ERP system implementation.

\section{LITERATURE REVIEW}

The proposed critical success factors shown in Figure 1 are derived from the literatures [6], [7], [8] and case study experienced by the author in Malaysian SME. These factors might be considered by Malaysian SME which attempt to implement ERP system in their plant to streamline their business process. The critical success factors are: (1) Top Management Commitment and Support, (2) Clear Understanding of Strategic Goals and Objectives, (3) IT Staff Support, (4) ERP Teamwork and Composition, (5) User Involvement, (6) Educational Level, (7) Project Champion, (8) Project Team Competence, (9) Effective Project Management, (10) Change management, (11) Organizational Culture, (12) Communication, (13) Cooperation, (14) Vendor Support, (15) Data Accuracy and Data Quality, (16) Suitability of Software and Hardware, (17) Testing and Troubleshooting, (18) Monitor and Evaluation of Performance. By understanding these factors, it can help Malaysian SMEs to implement ERP system successfully. The explanation of the proposed critical success factors based on previous literatures can be seen as follows.

\section{A. Top Management Commitment and Support}

Implementing an ERP system project needs a big support from the top management, especially in the early steps of such a project [9]. Middle management and staff are also as important as top management, but each of them has different roles [10]. Top management needs publicly and expressly to identify the project as a top priority [11]. Top management must be fully committed and have a willingness to allocate resources to the project [12]. This includes provision of required resources for the project and giving an appropriate amount of time and budget to get the job done [13].

\section{B. Clear Understanding of Strategic Goals and Objectives}

Set the strategic goals and objectives are important before even seeking top management support [14]. Clear strategic goals and objectives are essential to guide an ongoing organizational effort for ERP system implementation. SMEs must define why the ERP system is being implemented and how they successfully implement ERP system.

\section{IT Staff Support}

IT staff support is one of the critical factors for successful ERP system implementation. The idea of implementing ERP system would not appeal to SMEs that do not have a technology department and will lead to a negative culture shock in the working environment [15]. SMEs that lack of personnel that clearly understanding technology will find that adopting ERP system would have a rough time and will be highly unlikely change their old ways of work.

\section{ERP Teamwork and Composition}

The ERP project team should consist of the best people in organization [9], [11], [16]. SMEs should have a crossfunctional team for clearly understanding the organization's business strategy and process. Mix of consultants and internal staff are necessary to develop business and technical skills for ERP system implementation.

\section{E. User Involvement}

User involvement is important throughout ERP system implementation process, because end-users will be the potential users who use ERP system for handling their daily jobs. Educating and training the end-users can generate their resistance to using the new system [17].

\section{F. Educational Level}

The project team and end-users educational level issue often emerge in Malaysian SMEs for implementing new system. The personnel should have sufficient knowledge in adapting and manipulating the learning curve of the software. Lack of knowledge can be a failure factor for ERP system implementation.

\section{G. Project Champion}

The success of technological innovations is often linked to the participation of a champion, who performs important transformational leadership, facilitation, and marketing the project to the users [18]. This person is usually from the senior management level of an organization, which has authority to make changes happen in an organization.

\section{H. Project Team Competence}


Project team competence makes an impact on the implementation of system in information technology. Project team who has competence will be able to overcome the unexpected issue during implementation process. There has not been much research regarding this issue. However, SMEs have to look into different literatures from other fields about the reason where the importance of team competence has been well recognized [4].

\section{Effective Project Management}

Project team must be flexible and deal with the problems as they arise in the implementation process. In this case, effective project management methodology is a critical success factor for successful ERP system project. Anyone who has revisits the charter documents of a large-scale ERP project will see that the ultimate product is shaped by unanticipated and late breaking circumstances. It is a fact of business life that important things come up later rather than earlier in complex new projects [19].

\section{J. Change Management}

ERP system implementation is the improvement strategy of an organization which commonly involves change. On that account, responsiveness to internal users is critical for SMEs to avoid the difficulties associated with this change [20]. The first step in effectively managing change is to identify and evaluate the attitudes of end-users and influential groups [21]. This step may offer a good starting point in determining the resources of users' resistance to the ERP system [20]. A major strategy to overcome this issue is communication.

\section{K. Organizational Culture}

The success of ERP system implementation depends on users' acceptance and their willingness to work with the new system. The role of top management in providing the appropriate and effective leadership and support creating a culture that is conducive to effective ERP system implementation.

\section{Communication}

Communication across different business functions and departments is important. According to one author on IT project management, "communication is the oil that keeps everything working properly" [22]. As noted above, it means communication across different business functions and departments is important in an ERP context, because the main objective of ERP systems is to integrate the business functions [2].

\section{Cooperation}

People are naturally resistant to change and it becomes an issue in implementing new system without cooperation. An ERP project involves all of the functional departments and demands the effort and cooperation of technical and business experts as well as end-users.

\section{N. Vendor Support}

SMEs commonly do not have all the technical and transformational skills readily, for managing the ERP implementation on their own. Therefore, the collaboration with the IT vendors can actualize the successful project [10].

\section{O. Data Accuracy and Data Quality}

Data accuracy during the conversion process is much of the success of the ERP system implementation among SMEs. This stage of the implementation might also involve the cleaning up of suspect and unnecessary data [18], [23]. Based on the research study established by the author, Malaysian SMEs have weakness of data quality. They do not have complete data to implement ERP system. This issue could be a project failure in ERP system implementation.

\section{P. Suitability of Software and Hardware}

ERP system implementation requires at least basic IT infrastructure. Sometimes the use of ERP software is not compatible and appropriate for certain SMEs that do not have IT infrastructure, such as computer. SMEs with low IT infrastructure prior to an ERP system implementation will most probably unable to utilize the equipments for the new system optimally [15].

\section{Q. Testing and Troubleshooting}

The project team should consider the systems testing exercises during the final stage of implementation process, as well as simulation exercises before the system goes live [23]. The need for troubleshooting skills will be an ongoing requirement of part of implementation process [12].

\section{R. Monitor and Evaluation of Performance}

ERP system implementation is challenging, costly, and risky. Consequently, to achieve the desired benefits, the ERP system implementation must be carefully managed and monitored. Effective project planning and scheduling is the best way to overcome this issue.

\section{METHODOLOGY}

This study based on a single case study in Malaysian SME which attempted to implement ERP system. The critical success factors model which mentioned in this study was gathered based on research experienced by the authors and validated by a number of Malaysian SMEs. The survey was established in a group of experts in industries in Kuala Lumpur and Selangor. In that survey, the authors have given a questionnaire to the experts for investigating the ERP system implementation in their plants. Afterward, the authors asked the validation of the framework, which is designed based on the results of the questionnaire and observation. As a proof of concept, this framework is implemented in one of the SMEs in the industrial SMEs area in Selangor, Malaysia. Figure 1 shows the research approach to establish this study.

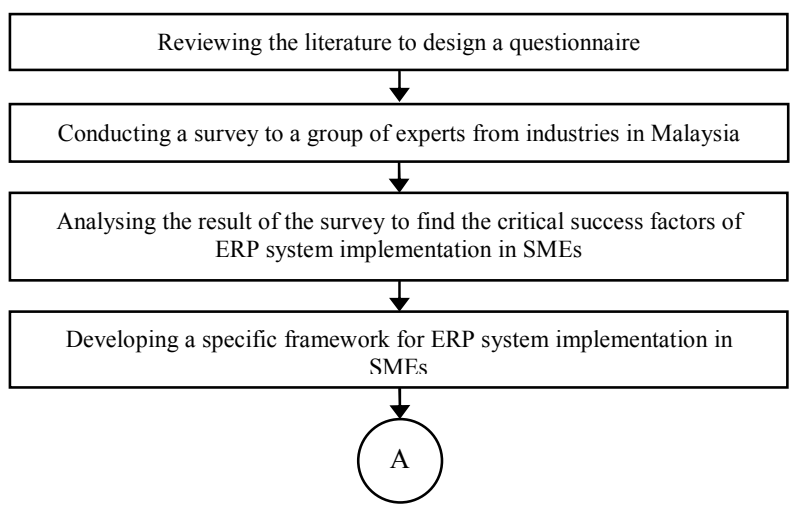




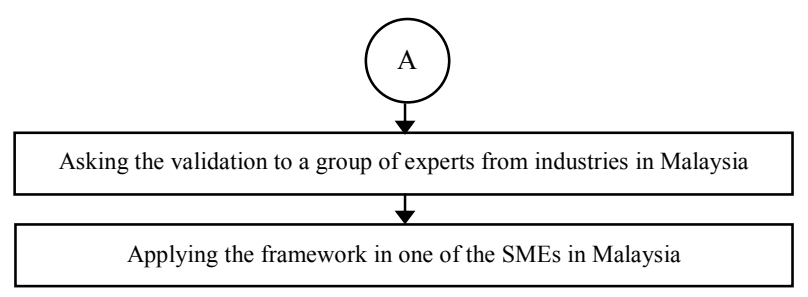

Fig. 1 The Research Approach

Most of Malaysian SMEs have the same idea with the proposed critical success factors model. Therefore, this model can be used by another Malaysian SMEs which has willingness to implement ERP system in their plant. The critical success factors model for ERP system implementation is shown in Figure 2 below.

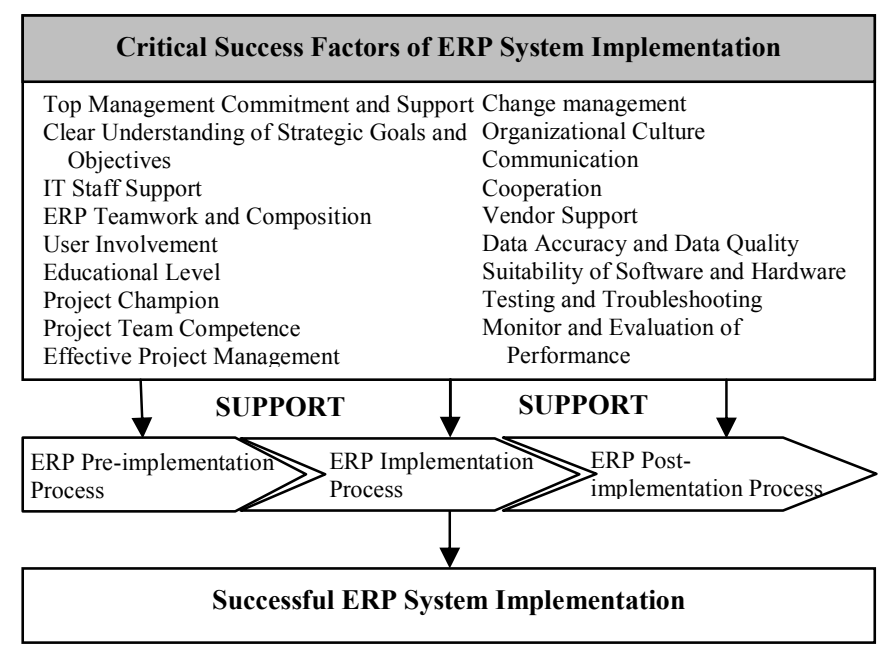

Fig. 2 Critical Success Factors Model for ERP System Implementation

There is a relation between critical success factors and ERP implementation process as shown in Figure 2. Critical success factors support ERP system processes: ERP Preimplementation process, ERP Implementation process, and ERP Post-implementation process, in order to achieve successful ERP system implementation.

\section{DISCUSSION}

SMEs define as companies in the manufacturing and service sectors with annual sales turnover not exceeding RM25 million and full time employees not exceeding 150 people [24]. Malaysian SMEs are involved in various industries. One of them is SMEs in the manufacturing sector.

The research experienced shows that ERP system adoption in Malaysian SMEs is still low, even that they have implemented ICT in their plants. Most Malaysian SMEs do not have awareness to implement high level information system to streamline their business processes due to its complexity and high cost of implementation. Generally SMEs which has large business level have willingness to implement ERP system. Conversely, SMEs with the lower business level do not attempt to implement ERP system because of avoiding from the risks.

International ERP vendors may have difficulty in entering most SMEs market in Malaysia, because their software packages are still not compatible to the needs of some SMEs in Malaysia. Most existing ERP software packages are only suitable for large companies. Besides the budget and market issues, SMEs also have problem with the complexity in implementing ERP system in their business operation, lack of strategic decision making, and acceptance of a new work culture. For that reason, it is necessary for SMEs and ERP vendors to understand the critical factors that can lead them to the successful of ERP system implementation.

The research conducted in Company $\mathrm{X}$ as one of SMEs in Malaysia which was established in Kuala Lumpur since 1988. Company X's sector is manufacturing in plastic products which bought ERP software from selected vendor. The objective of Company $\mathrm{X}$ for implementing an ERP system was basically operational reason. Management wanted to know about financial, production, logistics and sales reports in faster way, so that the management of Company $\mathrm{X}$ can improve the time for decision making. Figure 3 illustrates the ERP system implementation process in Company X.

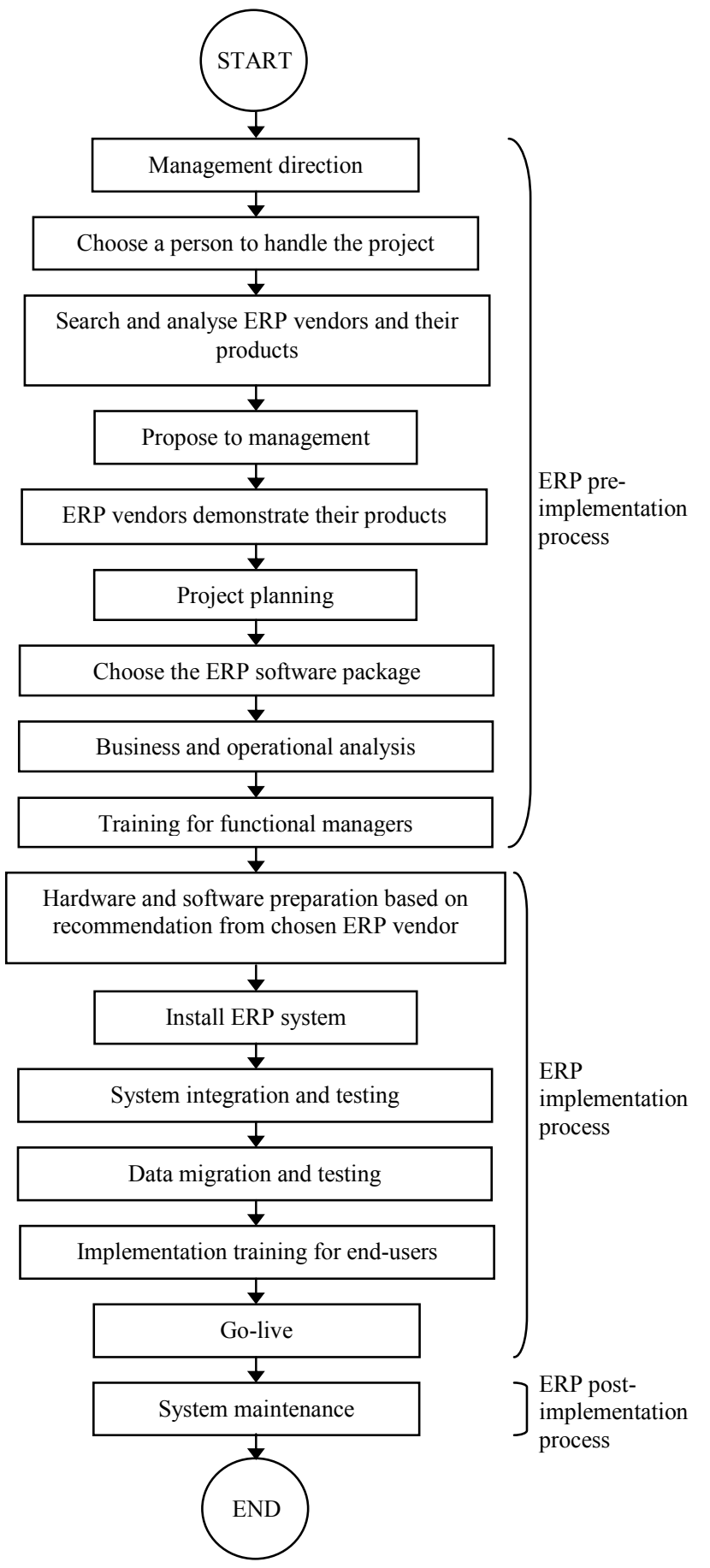

Fig. 3 The ERP System Implementation in Company X 
The process of an ERP system implementation in Company $\mathrm{X}$ is divided into three stages: pre-implementation process, implementation process and post-implementation process. The problems in implementing ERP system have occurred in every implementation stages. TABLE 1 shows the detail problems that are faced by Company $\mathrm{X}$.

TABLE I

\begin{tabular}{|c|c|}
\hline Implementation Stage & Problem \\
\hline Pre-implementation process & $\begin{array}{l}\text {-The top management did not try to } \\
\text { promote the benefits of ERP system } \\
\text { to the end-users. } \\
\text {-Insufficient education level and } \\
\text { knowledge transfer from the ERP } \\
\text { vendor to the end-users. } \\
\text {-Insufficient training to the end- } \\
\text { users. } \\
\text {-Lack of vendor support. } \\
\text {-High user resistance to change. } \\
\text {-High of staffs' turnover. } \\
\text {-Absorption of resources from other } \\
\text { companies. } \\
\text {-No recruitment for IT staffs. } \\
\text {-No scope management. } \\
\text {-Low quality of data. }\end{array}$ \\
\hline Implementation process & $\begin{array}{l}\text {-Lack of internal and external } \\
\text { communication. } \\
\text {-Lack of internal cooperation. } \\
\text {-Insufficient training to the end- } \\
\text { users. } \\
\text {-Lack of vendor support. } \\
\text {-High user resistance to change. } \\
\text {-High of staffs' turnover. } \\
\text {-Absorption of resources from other } \\
\text { companies. } \\
\text {-No recruitment for IT staffs. } \\
\text {-Low quality of data. }\end{array}$ \\
\hline Post-implementation process & $\begin{array}{l}\text {-Lack of vendor support. } \\
\text {-High user resistance to change. } \\
\text {-High of staffs' turnover. } \\
\text {-Absorption of resources from other } \\
\text { companies. } \\
\text {-No recruitment for IT staffs. } \\
\text {-Low quality of data. }\end{array}$ \\
\hline
\end{tabular}

The problems that are listed in TABLE 1 occurred in the previous ERP system implementation in Company $\mathrm{X}$. Currently the management of Company $X$ hired the IT manager, who is handling the ERP system implementation in Company X. In that implementation, the authors are involved as ERP team members to support the implementation.

In the present implementation, ERP project team has installed the ERP system. The end-users and top management have used the ERP software. Nevertheless, there are still many critical success factors, which are contained in the literature review, are not addressed by the project manager in implementing ERP system. This involves many problems that arise after implementation phase. One such problem is unlimited knowledge of end-users in understanding ERP system. The end-users have difficulty in using the ERP software. In their opinion, ERP system is not helpful to simplify the way their work. Therefore, there are many errors in term of data entry. These problems influence the effectiveness of ERP system to the business process in Company X.

\section{CONCLUSION}

As a conclusion, an organisation has to consider not only in technical factors for implementing an ERP system. There are functional factors, such as communication, cooperation, knowledge transfer, change management, user involvement and project team competence, which are critical to support the successful implementation of ERP system. SMEs still do not pay attention to these functional factors. Consequently, SMEs have to face the problems that should not be exists theoretically after implementation phase.

The research experience of this case study describes the real condition of implementing ERP system for other SMEs, especially Malaysian SMEs. As a result, the critical success factors are empirically proved to be considered by SMEs to gain the successful ERP system implementation.

\section{REFERENCES}

[1] P. Sharma, Enterprise Resource Planning, Aph Publishing Corporation, Newdelhi, 2004.

[2] T. H. Davenport, "Putting the enterprise into the enterprise system," Harvard Business Review, pp. 121-131, 1998.

[3] D. C. Hayes, H. E. Hunton, and J. L. Reck, "Market Reaction to ERP Implementation Announcements," Journal of Information Systems, vol. 15, pp. 3-18, 2001.

[4] T. L. Griffith, R. F. Zammuto, and L. Aiman-Smith. "Why new technologies fail?," Industrial Management, pp. 29-34, 1999.

[5] P. T. Kale, S. S. Banwait, and S. C. Laroiya, "Performance evaluation of ERP implementation in Indian SMEs", Journal of Manufacturing Technology Management, vol. 21 iss: 6, pp.758-780.

[6] T. C. Loh and S. C. L. Koh, "Critical elements for a successful enterprise resource planning implementation in small- and mediumsized enterprises", International Journal of Production Research, vol. 42, no. 17, pp. 3433-3455, 2004.

[7] M. R. Imtihan, Z. Baharum, M. S. Ngadiman and H. Haron, "Critical Factors in Ensuring the Success of Implementing Open Source ERP: Case Study in Malaysian Small Medium Enterprise", Proceedings of the $9^{\text {th }}$ Asia Pasific Industrial Engineering \& Management Systems Conference, 2008.

[8] A. Noudoostbeni and N. M. Yasin, "To Investigate the Success and Failure Factors of ERP Implementation within Malaysian Small and Medium Enterprises", in International Conference on Information Management and Engineering, IEEE Xplore, 2009.

[9] P. Bingi, M. K. Sharma, and J. K. Godla,"Critical Issues Affecting an ERP Implementation," Information Systems Management, vol. 16, pp. 7-14, June 1999.

[10] R. E. Walton and R. B. Mckersie, A Behavioral Theory of Labor Negotiations: An Analysis of a Social Interaction System, Cornell University Press, 1991.

[11] S. Wee. (2000) Juggling toward ERP success: keep key success factors high, ERP News. [Online]. Available: http://www.erpnews.com/erpnews/erp904/02get.html.

[12] C. P. Holland and B. Light, "A critical success factors model for ERP implementation," IEEE Software, pp. 30-35, May/Jun. 1999.

[13] H. J. Roberts and P. R. N. Barrar, "MRPII implementation: key factors for success," Computer Integrated Manufacturing Systems, vol. 5, pp. 31-38, 1992.

[14] D. P. Slevin and J. K. Pinto, "The project implementation profile: new tool for project managers," Project Management Journal, vol. 17, pp. 57-70, 1996.

[15] S. S. Shahawai and R. Idrus, "Pre-considered factors affecting ERP system adoption in Malaysian SMEs," in 12th International Conference on Computer Modelling and Simulation, 2010.

[16] S. Buckhout, E. Frey, and J. Jr. Nemec, "Making ERP succeed: turning fear into promise," IEEE Engineering Management Review, pp. 116123, 1999.

[17] M. Sumner, "Critical success factors in enterprise wide information management systems," in Proceedings of the Americas Conference on Information Systems (AMCIS), 1999, pp. 232-234.

[18] T. M. Somers, K. Nelson, and A. Ragowsky, "Enterprise resource planning (ERP) for the next millennium: development of an integrative framework and implications for research" in Proceedings of the 
Americans Conference on Information Systems (AMCIS), 2000, pp. 998-1004.

[19] S. Cliffe, "ERP Implementation," Harvard Business Review, pp. 16.

[20] M. Al-Mashari and M. Zairi, "Supply-chain re-engineering using enterprise resource planning (ERP) systems: an analysis of a SAP R/3 implementation case," International Journal of Physical Distribution \& Logistics Management, vol. 30, pp.296-313, 2000.

[21] A. Aladwani, "Coping with users resistance to new technology implementation: an interdisciplinary perspective," in Proceedings of the $9^{\text {th }}$ IRMA Conference, 1998, pp. 54-9.

[22] K. Schwalbe, "Information technology project management," Cambridge, USA, 2000

[23] Y. Yusuf, A. Gunasekaran, and M. S. Abthorpe, "Enterprise information systems project implementation: A case study of ERP in Rolls-Royce," International Journal of Production Economics, vol. 87, pp. 251-266, February 2004.

[24] (2009) SMIDEC website. [Online]. Available: http://smidec.gov.my/ 